\section{Comment on 'Midwives' experiences and views of giving postpartum contraceptive advice and long-acting reversible contraception: a qualitative study'}

We would like to thank Kirsty McCance and Sharon Cameron for their article ${ }^{1}$ that appeared in the July 2014 Journal issue.

We would like to share our experience in Lanarkshire with Journal readers.

We concur with the authors' three key message points. ${ }^{1}$ However, the Sexual and Reproductive Health team in Lanarkshire decided to grasp the opportunity to provide immediate contraception for extremely vulnerable postnatal women by training midwives to fit implants and by increasing their knowledge of all other methods of contraception.
It was recognised that vulnerable postnatal women needed instant access to better contraception. Collaboration with the Consultant Midwife and senior health clinicians in Lanarkshire took place with the aim of providing immediate postnatal contraception for vulnerable women. The Sexual and Reproductive Health team ran a halfday theoretical course on contraception and transmitted infection screening for interested midwives. This training included model arm training for implant fitting and the midwives subsequently attended practical implant training. It has to be said that midwives are well placed to fit implants as they are familiar with injecting lidocaine for episiotomy repairs.

During the period May 2013 to March 2014, 84 women had an implant inserted in the immediate postnatal period by the midwives.

There have been two training days, one in February 2013 that was repeated in 2014. To date 12 midwives have completed the training. Most of the abovementioned insertions were undertaken by the original three midwives who trained, and there has been a demand from other midwives for more training. A detailed review of this service is now taking place.

This has been a successful project with positive feedback from the midwives concerned. Participants felt that the training improved their knowledge of contraception but also empowered them to provide effective contraception to three vulnerable groups, namely teenagers, substance misusers and women with chaotic lifestyles for whatever reason. It has also enabled some of these women who needed other long-acting contraceptive methods to be fast-tracked to our service. Most importantly, it has also greatly improved our links and communication with local midwives.

Eleanor Smith, MBChB, FFSRH

Associate Specialist, Lanarkshire Sexual \& Reproductive Health, Coathill Hospital, Coatbridge, UK: Eleanor.Smith2@lanarkshire.scot.nhs.uk

Anne McLellan, MRCOG, PgDip Forensic Science Lead Clinician, Lanarkshire Sexual \& Reproductive Health, Coathill Hospital, Coatbridge, UK; Anne.McLellan@lanarkshire.scot.nhs.uk

Competing interests None.

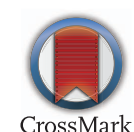


J Fam Plann Reprod Health Care 2014;40:312-313. doi:10.1136/fprhc-2014-101048

\section{REFERENCE}

1 McCance K, Cameron S. Midwives' experiences and views of giving postpartum contraceptive advice and long-acting reversible contraception: a qualitative study. J Fam Plann Reprod Health Care 2014;40:177-183. 